\title{
Research on the Training Model of Innovative Talents in Visual Communication Design Specialty
}

\author{
Yubin Wu \\ Guilin University of Aerospace Technology, Guilin 541004, China \\ wyb19870713@qq.com
}

\begin{abstract}
Through a comprehensive analysis of the current situation of the development of visual communication design teaching in Colleges, this paper explores the implementation methods of visual communication design teaching mode from the perspective of innovative personnel training, and further improves the professional ability and professional teaching quality of graduates of visual communication design major in Colleges and universities. To provide more professionals in the field of design for the society.
\end{abstract}

Keywords: Visual communication design major; Innovative talents; Training mode.

\section{Introduction}

Colleges and universities are the key bases for training high-quality talents. They have distinct innovative educational objectives and shoulder the responsibility of training and delivering high-quality talents for the society. As a key specialty in the modern art design education system in China's universities, visual communication design should also promote teaching practice and innovation around the characteristics of innovative education, to cultivate high-quality innovative design talents. However, in view of the reality of Chinese universities, due to many historical factors, the existing guidance of innovative education in visual communication is not strong, and the level of education and teaching in schools lags, so the teaching situation is not optimistic [1]. Faced with this situation, colleges and universities have changed their thinking and explored the reform of visual communication education based on the perspective of innovative personnel training, in order to explore the breakthrough of education, meet the requirements of the development situation of innovative education, and ensure the sustainable development of design education in China.

\section{The Current Situation of Education of Visual Communication Design Specialty and the Target of Training Talents}

The professional education of visual communication design in Colleges and universities has the characteristics of both artistry and timeliness, economy and technology, culture and sociality, communication and openness. The development trend of visual communication design itself is to design packaging for enterprises, shape brands, expand markets, enhance corporate image and guide elimination. Consumer consumption and the creation of visual culture are moving forward. Therefore, in this economic-led era of picture reading, the goal of visual communication design education in Colleges and universities must be closer to the needs of market economy development [2].

The continuous change of China's economic development has changed the way of life and lifestyle of modern people. The demand for aesthetic stimulation and visual culture shock has become more and more intense. Comprehensive culture has put forward new interpretations for the improvement of expression context and the innovation of design concept. Visual communication design is also gradually moving from two-dimensional plane to three-dimensional space. These new market environment changes have put forward higher requirements for the education of visual communication design in Colleges and universities. In order to adapt to the international market competition, meet the needs of professional life-long development, have the technical application ability and innovation ability in the professional field has become the main goal of the current training of visual communication professionals in Colleges and universities. 


\section{Visual Communication Education Reform Strategy based on the Perspective of Innovative Talents Training}

\subsection{Perfecting the Course Construction and Highlighting the Characteristics of Personnel Professional Training}

First, set up a scientific curriculum system. Visual communication design is a new frontier professional discipline, which was initially established by some foreign art colleges. As a comprehensive art specialty spanning humanities and social sciences, it concentrates on the concept of "art and humanities". Therefore, the connection between vision and art guidance should be reflected in the course design. Fusion of the two, and give play to the combined force of the two. Secondly, in view of the lack of comprehensive understanding of the subject of visual communication design among college students, colleges and universities should add appropriate teaching modules such as the history of the development of visual communication specialty. In this way, students can understand the artistic connotation of visual communication more comprehensively and deeply, and fully realize the importance of the subject.

Second, improve the teaching content of textbooks. Textbooks serve for curriculum practice. In view of this attribute, colleges and universities should embody the principle of professionalism in compiling textbooks for teaching curriculum practice, and formulate general textbooks suitable for various levels of education, so as to better embody the professionalism of visual communication education. In this process, colleges and universities can select and formulate new textbooks according to the educational objectives and tasks of visual communication specialty, and the choice of content should also reflect the comprehensiveness and comprehensiveness of professional teaching. Secondly, it is necessary to clarify the central idea of the content of the textbook, reasonably introduce some popular design factors, so that the textbook not only has the foundation, but also highlights the practicality and the times. In addition, we should accurately grasp the principles of scientificity and systematicness when constructing the framework of conceptual knowledge, and follow the order of teaching content from shallow to deep [3].

\subsection{Developing Practical Activities to Improve Ability in Experience Education}

One of the important attributes of visual communication design specialty is practicality. Teachers must base on the essential attributes of visual communication design discipline and guide students to actively participate in various related practical activities in order to enable students to improve their abilities in practice. We can see that the vast majority of students in the usual classroom performance is not bad, comprehensive evaluation can also achieve excellent results, but once they participate in the actual project development, they will miss out a hundred, the final development effect is imaginable. In the final analysis, this is mainly due to their usual practice and exercise opportunities are too few. In view of this situation, teachers should actively create platforms and conditions for students, and strengthen the practical teaching of students' visual communication design. For example, schools can organize students to study in practice bases, individually provide students with internship opportunities according to their needs, so that students can really participate in project development in the latter part of the internship, so that students can develop their own practical design and production ability in the actual project development and production. At the same time, through participating in cultural and creative industry cooperation projects, students can be guided to use their own knowledge and skills, make comprehensive use of artistic conception and design technology, and carry out targeted design practice activities in conjunction with actual projects [4]. This reflects the visual communication design education in Colleges and universities, and constantly explores a new curriculum system and teaching mode to adapt to market changes, ultimately making visual communication design better serve the human society.

\subsection{Implementing Project Teaching to Cultivate and Develop Students' Thinking Ability}

The biggest difference between traditional art design form and visual communication design lies in the change of design technology. Visual communication design can not only present three- 
dimensional effect for the public, but also use its own information design technology to realize the simulation of design. Designers can interact with works, and use different ways to trigger the transformation of works - touch, space movement, voice and so on, to change the image, shape and significance of works. Therefore, in addition to strengthening the education of students' professional knowledge, colleges and universities should also integrate the practical links into students' practical training projects, so that students can make use of computer, printer, scanner, burner, digital camera, digital camera and other machine equipment to draw and design by hand and improve their design ability. Of course, students can also use the equipment in the training project, using the unique performance techniques of these equipment, to integrate the relevant elements of sound, text, graphics and so on, so that their design concept can be fully and multi-dimensional.

\section{Summary}

Under the background of gradual adjustment and improvement of higher education system structure, visual communication design, as a new professional discipline, can keep up with the train of the times, has become an important issue for educators. In order to meet the requirements of students majoring in visual communication design in the field of art design, relevant teaching staff should constantly sum up teaching experience according to the actual situation of students, promote the innovation of educational mode, concentrate on the development and cultivation of innovative visual communication design professionals.

\section{Acknowledgments}

This work is carried out with the support of the research project of teaching reform of Vocational Education in Guangxi in 2017. (NO. GXGZJG2017B084).

\section{References}

[1]. Liu L. Reflection on Practice Teaching Reform of College Visual Communication Design[C]// International Conference on Arts. 2016.

[2]. Zhang X. A Research on Multidimensional Compound Talent Training Mode Take Visual Communication Design Major as an Example[C]// International Conference on Arts. 2016.

[3]. Wei WU, Zuoming ZHONG, Min CHEN. A Study on the Training Mode of Discipline-oriented Innovative and Entrepreneurial Talents - Taking Agricultural, Forestry and Normal Universities as an Example[J]. Asian Agricultural Research, 2018, 10(12):80-82.

[4]. Cai W, Che J, Yu S. Cultivating System of Applied Talents in Building Environment and Facilities Engineering Specialty[C]// Proceedings of the 2012 3rd International Conference on E-Business and E-Government - Volume 04. 2012. 